\title{
Effectiveness of Tele-Prescription of Therapeutic Physical Exercise in Patellofemoral Pain Syndrome during the COVID-19 Pandemic
}

\author{
Manuel Albornoz-Cabello ${ }^{1}\left(\mathbb{D}\right.$, Cristo J. Barrios-Quinta ${ }^{2}{ }^{(}$, Ana M. Barrios-Quinta ${ }^{3}$, Isabel Escobio-Prieto ${ }^{1, *(1)}$, \\ María de los Angeles Cardero-Durán ${ }^{4}$ and Luis Espejo-Antunez ${ }^{4}$
}

1 Department of Physiotherapy, Faculty of Nursing, Physiotherapy and Podiatry, University of Sevilla, 41009 Sevilla, Spain; malbornoz@us.es

2 Physiotherapy Unit, Andalusian Health Service, 41005 Sevilla, Spain; cristo.barrios@gmail.com

3 Nursing Unit, Andalusian Health Service, 41005 Sevilla, Spain; anam.barrios.sspa@juntadeandalucia.es

4 Department of Medical-Surgical Therapy, Medicine Faculty, University of Extremadura, 06071 Badajoz, Spain; m.angeles.cardero@gmail.com (M.d.l.A.C.-D.); luisea@unex.es (L.E.-A.)

* Correspondence: iescobio@us.es

check for

updates

Citation: Albornoz-Cabello, M.; Barrios-Quinta, C.J.; Barrios-Quinta, A.M.; Escobio-Prieto, I.; CarderoDurán, M.d.1.A.; Espejo-Antunez, L. Effectiveness of Tele- Prescription of Therapeutic Physical Exercise in Patellofemoral Pain Syndrome during the COVID-19 Pandemic. Int. J. Environ. Res. Public Health 2021, 18, 1048. https://doi.org/10.3390/ ijerph18031048

Received: 28 December 2020

Accepted: 20 January 2021

Published: 25 January 2021

Publisher's Note: MDPI stays neutral with regard to jurisdictional claims in published maps and institutional affiliations.

Copyright: (C) 2021 by the authors. Licensee MDPI, Basel, Switzerland. This article is an open access article distributed under the terms and conditions of the Creative Commons Attribution (CC BY) license (https:/ / creativecommons.org/licenses/by/ $4.0 /)$.

\begin{abstract}
The health crisis caused by COVID-19 has had a huge impact on the provision of physiotherapists' services during the pandemic. Patellofemoral pain syndrome (PFPS) is a major health problem and one of the most common causes of pain in the front of the knee in outpatients. The objective was to evaluate the effectiveness of a therapeutic physical exercise (TPE) program supervised by a physiotherapist using telematic channels in reducing pain and disability in a sample of 54 patients with PFPS in the Physiotherapy Service of the San José de la Rinconada Health Center (Seville). Subjects were evaluated pre- and post-intervention (4 weeks-12 treatment sessions). An analysis was made of perceived pain - using the visual analog scale (VAS) and the DN4 neuropathic pain questionnaire-and functional balance-through the Kujala Score test and the Lower Extremity Functional Scale. The supervised TPE program in patients with PFPS produced a reduction in pain: VAS $\mathrm{F}_{1,52}=8.68(p=0.005) \eta^{2}=0.14$ and DN4: $\mathrm{F}_{1,52}=69.94(p=0.000) \eta^{2}=0.57$; and in Lower Extremity Functional Scale (LEFS) disability: $\mathrm{F}_{1,52}=19.1(p=0.000) \eta^{2}=0.27$ and KUJALA: $\mathrm{F}_{1,52}=60.28(p=0.000) \eta^{2}=0.54$, which was statistically significant $(p=0.000$ for $p<0.05)$. Hence, the TPE program presented was effective in reducing pain and disability in patients with PFPS.
\end{abstract}

Keywords: therapeutic physical exercise; patellofemoral pain syndrome; physiotherapy

\section{Introduction}

The period of time covering the present study is unprecedented. On 14 March 2020, the Government of Spain decreed a state of emergency, thereby beginning a period of confinement in order to stop the spread of the SARS-CoV-2 virus. This situation forced face-to-face care of patients attending the Physiotherapy Rooms in Primary Care Centers on an outpatient basis to be cancelled [1]. From that precise moment, physiotherapists in the primary care basic teams began to think of alternatives in order to maintain physical activity in their patients. Therapeutic exercise routines would make it possible to maintain the therapeutic goals of the different programs being carried out depending on their pathology.

It was a question of developing a labor of health education in the population being cared for by said physiotherapy rooms. Explaining the basic measures of prevention of the spread of the virus (hand hygiene, face masks, avoiding social contact, etc.) was necessary, as well as eliminating the techniques that would require contact, whilst at the same time providing self-management and self-care tools that matched the pathology of each patient, all of this while prioritizing telecare, recurring to telematic resources (telephone calls, emails, audio-visual resources, links to online material, etc.) [2]. Some studies have suggested a high social acceptance and confidence of patients toward telehealth in trauma 
care, especially for real-time diagnosis and remote treatment [3]. In addition, the specific e-Health and telemedicine programs implemented in the evaluation and treatment of musculoskeletal problems can reduce health costs. These programs may generate significant impact on patients living in rural or remote areas and increase adherence to treatment [3]. At the initial stage of the global pandemic declaration by the $\mathrm{WHO}$, this was the only possibility of continuing to provide services and avoiding risks to health professionals. In this case, primary care physiotherapists, given the lack of personal protective equipment at the beginning of the pandemic, needed to suspend in-person services.

Patellofemoral pain syndrome (PFPS) is a common musculoskeletal problem, characterized by pain in the front of the knee and tending to become chronic [4]. Although it affects the whole population, its incidence is greater in adolescents and young adults $[5,6]$.

PFPS has been associated with osteoarthritis of the knee and a high body mass index, but in a recent study, it was observed that this is not true in adolescents [7]. Patients usually describe an increase in symptoms on going up and down stairs, squatting, running, or sitting for a long time; since these activities increase compressive load forces in the patellafemoral articulation [8].

PFPS continues to be one of the most common and challenging musculoskeletal issues facing physiotherapists and sports medicine professionals [9].

Even though the pain associated with PFPS is characteristic, the cause of this pain remains unknown. Traditionally, PFPS has been related to damage of the articular cartilage; however, we know that articular cartilage is aneural [10]. There exist a variety of pathologies that can present signs and symptoms similar to PFPS, wherefore it is used to refer to all pain in the front of the knee [11].

The lack of understanding of the etiology and pathology associated with patellofemoral pain and dysfunction is reflected in the great number of therapeutic options to deal with PFPS. Conservative treatments are common, above all initially, and physiotherapy is one of the commonest interventions used [9].

Physiotherapeutic treatments often include the strengthening of the vastus medialis muscle of the quadriceps to promote active stabilization of the patella inside the trochlea of the femur, as well as manual therapy procedures, patellar realignment through taping, stretching, and therapeutic exercise [12-14]. Although these treatments seem to be based on theoretical reasoning, the evidence as to the effectiveness of these interventions is not well established [11].

Therapeutic physical exercise (TPE) constitutes one of the most valuable tools in our therapeutic arsenal. Adequate prescription tailored to each patient depending on their pathology, prior state of health, and prior levels of physical activity is a demand that the health system and society places on our backs. This entails the configuration of the physiotherapist as an expert in TPE. They must supervise and optimize the TPE program, adapting it to each patient, monitoring the prior and aspirational levels of physical activity in terms of both quantity and quality. In addition, the physiotherapist must identify any psychosocial barriers that might hinder the adherence of patients to the prescribed TPE programs. In short, the physiotherapist becomes the guide of the patient who must take the reins of their health and take on a proactive role in the face of their pathology $[4,15]$.

TPE and the integration of individual and group health education, in the activity of the primary care physiotherapist, afford greater control of repetitive demands on physiotherapy in the medium-term. Hence, supervised TPE has been hailed as one of the most effective tools in resolving problems deriving from chronic conditions where the reduction of pain and disability are the main objectives to be achieved [16]. The purpose of this study is to evaluate the effectiveness of a TPE program in reducing pain and disability, to quantify the decrease in pain in the front of the knee, and to appraise the improvement in functional disability in patients with PFPS after treatment with TPE supervised by a physiotherapist via telematic channels. 


\section{Materials and Methods}

\subsection{Study Design}

The present study is a longitudinal and prospective clinical trial conducted in the Physiotherapy Service of the San José de la Rinconada Health Center (Seville, Spain), dependent on the Andalusian Health Service. This study was supervised by the institutional ethics committee CEI University Hospital Virgen Macarena and Virgen del Rocio, with ethics approval number 41255cfcgab78019fga8501bb354b0ba4b15a804, registered in the Australian New Zealand Clinical Trials Registry: ACTRN 12619001457134, available at http: / / www.anzctr.org.au/Trial/Registration/TrialReview.aspx?id=377666\&isReview= true and found to be in agreement with the Declaration of Helsinki.

\subsection{Participants}

The target population that this protocol was aimed at was made up of all patients diagnosed with unilateral or bilateral PFPS belonging to the health area of the Basic Health Area of la Rinconada (Seville), with over 36,000 potential users. Inclusion criteria were patients diagnosed with PFPS of over a 6 month evolution, aged between 18 and 70 years. The exclusion criteria were presenting cognitive alterations and having undergone conservative or surgical treatment of the affected knee less than 6 months previously.

\subsection{Sampling and Randomization}

The convenience sampling method was used based on previous studies [17], an appropriate formula for the comparison of two proportions. The total number of patients who began the study was $60(30+30)$, and only 6 patients $(3+3)$ did not finish the study (due to dropping out or not answering the appointment or supervision calls). The final estimated sample size with a $10 \%$ dropout was equal to 27 individuals in each group $(\alpha=0.05, \beta=0.2)$. Eligible patients were randomly divided into two groups after providing written informed consent with the epidemiological data analysis program (EPIDAT) [18] program. All of them were Caucasian subjects. The first control group ( $\mathrm{C}$ group) received indications via telematic channels from their physiotherapist following the Spanish Society of Rehabilitation and Physical Medicine (SERMEF) indications [17], whereas the second TPE group, as well as receiving the indications via telematic channels from their physiotherapist following SERMEF indications [19], also received telephone advice at least three times a week over the four-week period that was the object of the study.

\subsection{Dependent Variables}

Measurements of the different variables of the study were made at two times, at the beginning thereof and after a four-week period, which coincided with the end of the intervention or treatment plan (12 home-based TPE sessions supervised by the physiotherapist via telematic channels).

The dependent variables considered in the heart of our research were (i) the perception of pain by the visual analog scale (VAS) which consists of using a validated scale, $10 \mathrm{~cm}$ long (0-10), where subjects place themselves from (0) lack of pain to (10) the worst pain bearable; (ii) perception of neuropathic pain, established through the DN4 questionnaire [20]; (iii) functional disability, quantified using the Kujala Score [21] and the Lower Extremity Functional Scale (LEFS) [22]; and (iv) an anthropometric study of the knee was also performed [5].

\subsection{Protocol of Intervention}

Interventions. Patients in the TPE group learned strengthening, endurance, flexibility, and an active range of motion exercises. A training program was created (Table 1) based on SERMEF indications [19]: above all, to activate the vastus medialis of the quadriceps muscle; to produce an authentic effective break to the lateralizing tendency of the patella during knee extension movements; as well as to work on the hamstrings, which are essential so that there is a balance of forces acting on the knee [12]; and to work on the tibia 
internal rotator muscles and strengthening of the triceps surae, thereby decreasing patellar pressure, owing to the posterior displacement of the lower extremity of the femur (synergy of quadriceps and triceps surae).

Table 1. Training program. Patellofemoral pain syndrome basic plus stretches.

\begin{tabular}{ccc}
\hline Exercise & Starting Position (sp) & Execution \\
\hline straight-leg lift & $\begin{array}{l}\text { Raise straight leg with knee in } \\
\text { extension about } 30 \mathrm{~cm} \text { from the } \\
\text { ground. Hold for 5" and slowly } \\
\text { return to SP. Sets (S): } 1 / \text { Repetitions }\end{array}$ \\
(R): 5
\end{tabular}

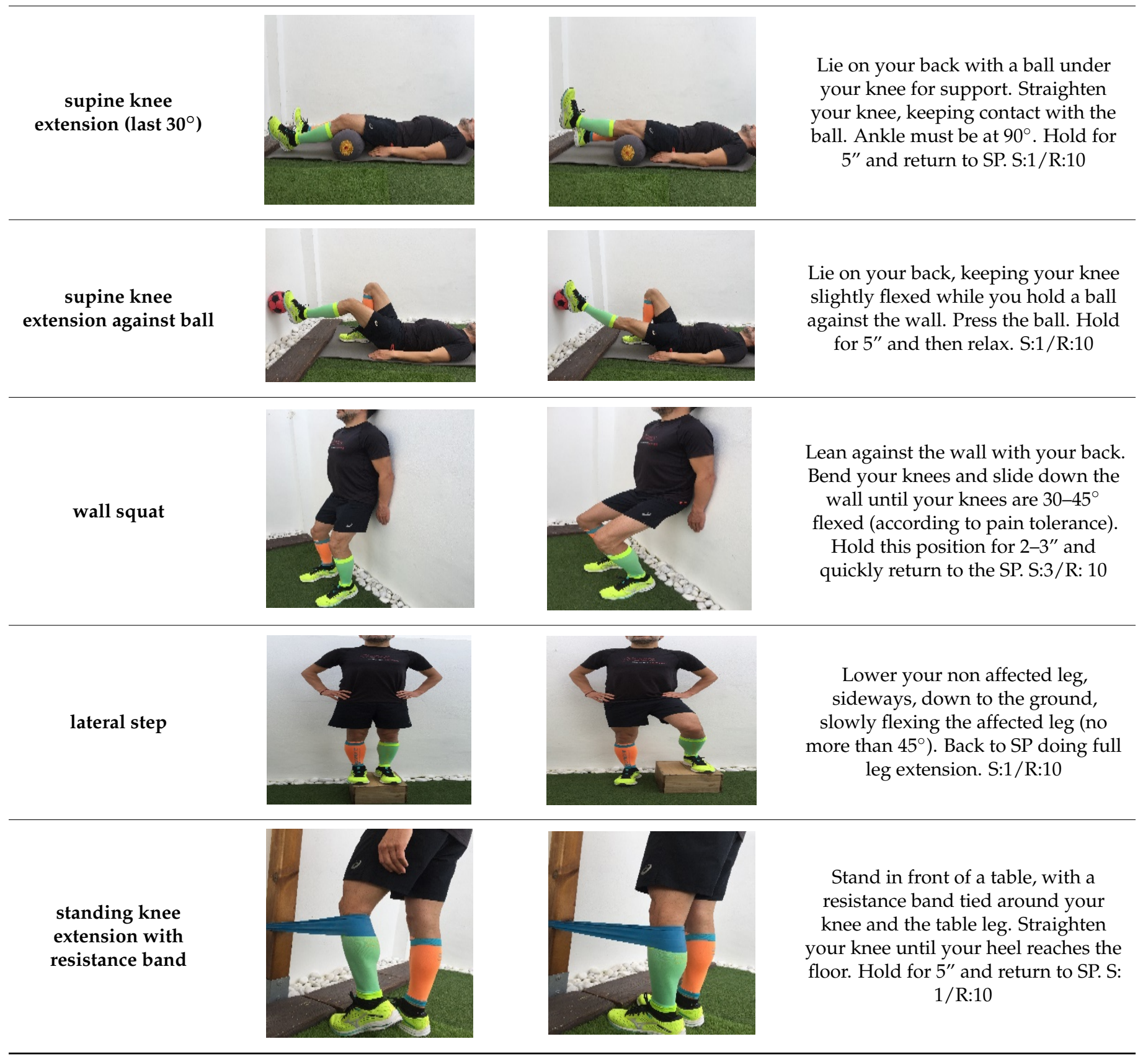


Table 1. Cont.

\begin{tabular}{|c|c|c|c|}
\hline Exercise & Starting Position (sp) & Execution & Explanation \\
\hline $\begin{array}{l}\text { standing quadriceps } \\
\text { stretch }\end{array}$ & & & $\begin{array}{l}\text { Stand on one leg leaning on a wall. } \\
\text { Bend your knee and hold your foot } \\
\text { with your hand. Passively bring the } \\
\text { heel toward your buttock until a } \\
\text { stretch is achieved. Hold for } \\
\text { 10-30"and release. S: } 1 / \text { R: } 5\end{array}$ \\
\hline $\begin{array}{c}\text { standing hamstring } \\
\text { stretch }\end{array}$ & & & $\begin{array}{l}\text { Tilt the body forward preventing the } \\
\text { knee from bending and keeping the } \\
\text { lumbar spine straight. Hold it for } \\
\text { 10-30". S:1/R: } 5\end{array}$ \\
\hline $\begin{array}{c}\text { standing triceps surae } \\
\text { stretch }\end{array}$ & & & $\begin{array}{l}\text { Stand leaning into the wall, with the } \\
\text { affected foot behind the non-affected } \\
\text { one. Bend your elbows and the } \\
\text { non-affected knee, keeping your } \\
\text { affected knee straight and heel on the } \\
\text { floor, until a stretch is achieved. Hold } \\
\text { for } 10-30^{\prime \prime} \text { and the release. S: } 1 / \mathrm{R}: 5\end{array}$ \\
\hline $\begin{array}{l}\text { sitting iliotibial band } \\
\text { stretch }\end{array}$ & & & $\begin{array}{l}\text { Sit on the floor with the affected leg } \\
\text { crossed over the other one. Turn your } \\
\text { torso to the affected side while you } \\
\text { pull your affected knee up towards } \\
\text { the opposite shoulder, until a stretch } \\
\text { is achieved. Hold for } 10-30^{\prime \prime} \text { and } \\
\text { release. S: } 1 / \text { R: } 5\end{array}$ \\
\hline
\end{tabular}

Then, they received a pamphlet containing descriptions and pictures detailing the above exercises (Table 1). Patients were asked to continue these exercises three times a week for four weeks (total of 12 sessions). They were told to place a cold pack (or similar) on their knees for $20 \mathrm{~min}$ before each session. A physiotherapist was responsible for making contact with patients via phone call and email three times a week where patients explained their exercise program and consulted their doubts about the execution. In this manner, the specialist remotely monitored the progress of the exercises and maintained principles of daily activities and symptom improvements. The physiotherapist asked patients to carry out their exercises as instructed by the pamphlet they received.

In the $C$ group, patients performed the same exercises as the TPE group, after being instructed by the physiotherapist on the exercises to be done at home but with no phone call control.

Pre- and post-treatment evaluations. In both groups, after acquiring demographic data, the intensity of knee pain was assessed with the VAS before the first session of treatments. Then, the KUJALA score, LEFS, and DN4 test were filled out by the physiotherapist 
to measure neuropathic knee pain, symptoms, and physical function throughout the day. Patients were also provided with $X$ Index for evaluation of physical function. The KUJALA and DN4 scores were normalized ((acquired score/total possible score) $\times 100)$. In accordance with previous studies [17], participants were re-evaluated using the same scales at the end of four weeks to assess the effects of each treatment (Figure 1).

Patient Enrolment: One PHCC of the Andalusian Health Service (Seville) that include physiotherapy in primary care for outpatients who have agreed to participe. The PHCC will proceed with the recruitment. Potentially eligible patients are informed of the date of the appointment with the time and place (usual hospital) for an evaluation with a physiotherapist blinded to the intervention.

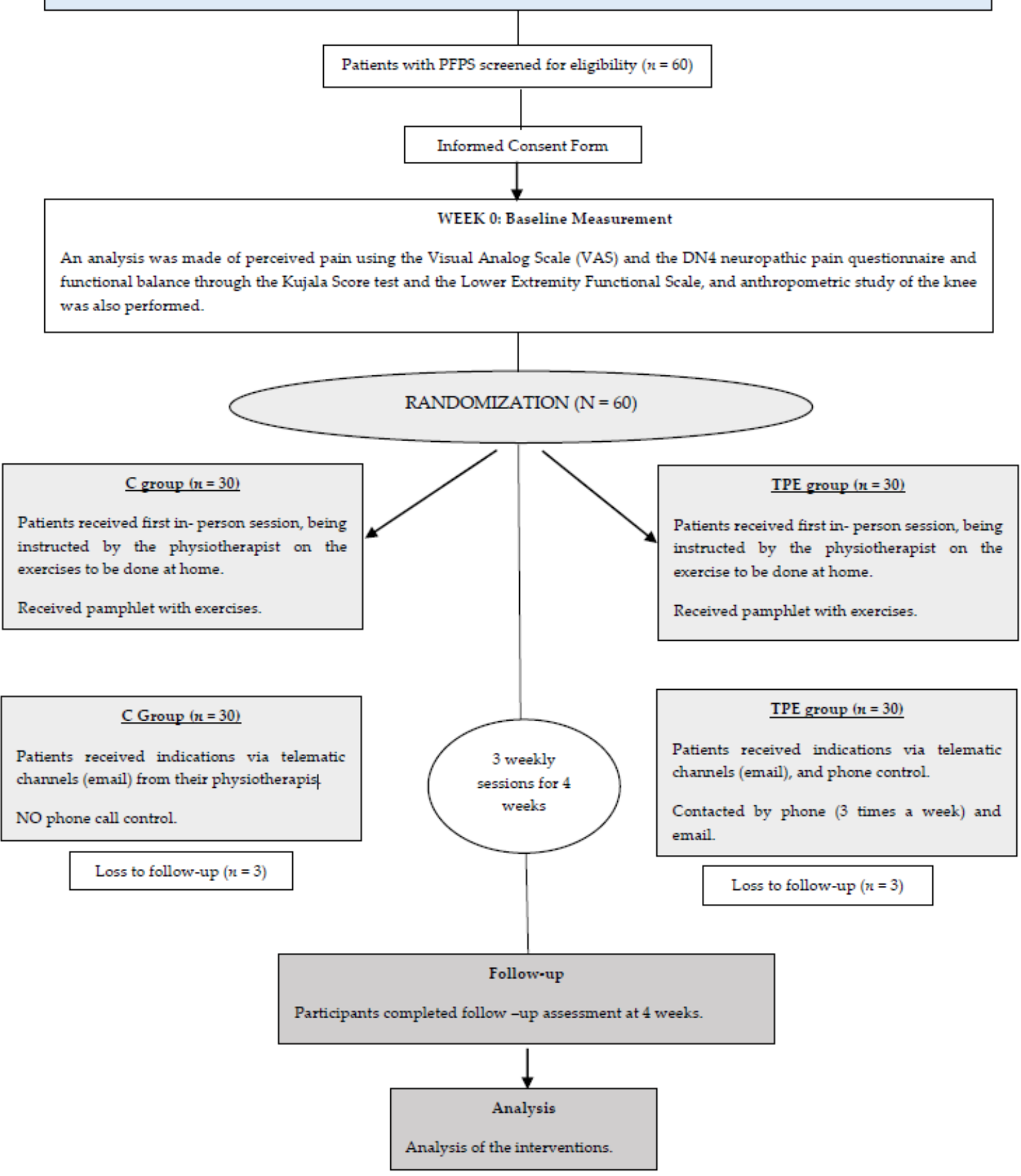

Figure 1. Design and flow participants through the trial. PHCC, primary healthcare centre; VAS, visual analog scale; TPE, therapeutic physical exercise group. 


\subsection{Statistical Analysis}

The sample size calculation was based on the detection of (1) an improvement of $15 \%$ in self-perceived pain intensity [23] and (2) a difference of $>9$ points in LEFS score at inter-group comparison after the treatment [24] and $>10$ points in the Kujala score. Taking into account a one-tailed hypothesis, an alpha value of 0.05 , a desired power of $80 \%$, and a large effect size $(f=0.2), 26$ participants were required per group of treatment $(G$ * Power, version 3.1.9.2).

The statistical analysis of the data was carried out using PSW Advanced Statistics (SPSS Inc, Chicago, IL) version 24.0. Data were reported as mean (standard deviation) and confidence intervals (IC 95\%). Firstly, the normal distribution of variables was verified by the Shapiro-Wilk test after descriptive analysis. The Levene test was used to assess the homogeneity of variances. Linearity was assessed by bivariate dispersion graphics of residual values observed from the expected values. Comparisons between groups were made for demographic and clinical data of reference using Student's t-test for continuous variables and Pearson's chi-square test for categorical variables. All analyses followed the intention-to-treat principle, and the groups were analyzed as randomized.

Differences in the measurements were detected by analysis of covariance (ANCOVA) to evaluate each dependent variable by age, height, weight, and body mass index, and as a variable factor the group (group TPE versus C). Eta square $\left(\eta^{2}\right)$ was used to calculate the effect size (small when $0.01 \leq \eta^{2} \leq 0.06$; medium when $0.06 \leq \eta^{2}>0.14$; large when $\left.\eta^{2}>0.14\right)$. Statistical significance was determined at $p<0.05$.

\section{Results}

\subsection{Description of the Sample}

A total of 60 subjects, aged between 25 and 67 years, were selected for the trial. After the inscription phase, the final sample included 54 individuals $(n=54), 26$ men and 28 women; mean age (SD) was 51 years (10.1). Of the affected knees, 29 were right $(54 \%)$ and 25 left $(46 \%)$. Of the subjects, 24 had an educational level of primary studies $(44 \%)$; 18 , secondary (34\%); and 12 , university $(22 \%)$. Of the sample subjects, 38 were employed in the service sector $(82 \%)$ and 10 in construction $(18 \%)$.

In relation to the patient diagnoses: 23 with patellar tendinitis (44\%), 21 with gonarthrosis $(40 \%), 7$ with chondromalacia patella $(12 \%)$, and 3 with bursitis $(4 \%)$ took NSAIDS and analgesics, while 28 subjects (52\%) took nothing.

Table 2 shows the mean values and standard deviation of the main variables, both as a whole and for each study group (experimental group and control group) and their statistical significance $(p>0.05)$, confirming that the groups had equivalent values at the beginning of the study.

Table 2. Baseline characteristics of study groups.

\begin{tabular}{ccccc}
\hline & $\begin{array}{c}\text { Total Sample } \\
(\boldsymbol{n}=\mathbf{5 4})\end{array}$ & $\begin{array}{c}\text { TPE Group } \\
(\boldsymbol{n}=\mathbf{2 7})\end{array}$ & $\begin{array}{c}\text { C Group } \\
(\boldsymbol{n}=\mathbf{2 7})\end{array}$ & $\boldsymbol{p}$-Value * \\
\hline Mean age (years) & $51(10.1)$ & $51(11.0)$ & $51(9.37)$ & 0.979 \\
Height (cm) & $167(11.0)$ & $169(11.7)$ & $165(10.0)$ & 0.176 \\
Weight (kg) & $81(16.8)$ & $82.8(17.8)$ & $79.1(15.8)$ & 0.411 \\
Body Mass Index & $28.7(4.8)$ & $28.6(4.3)$ & $28.9(5.4)$ & 0.827 \\
LEFS (\%) & $46(12.4)$ & $45(15.2)$ & $47(8.9)$ & 0.530 \\
KUJALA (\%) & $49(14.2)$ & $49(14.9)$ & $50(13.7)$ & 0.865 \\
DN4 (0-10) & $3.8(1.61)$ & $3.7(1.2)$ & $3.8(1.9)$ & 0.933 \\
VAS (mm) & $61(15.2)$ & $58(12.1)$ & $63(17.6)$ & 0.169 \\
FLEXION $\left(^{\circ}\right)$ & $118(12.3)$ & $117(11.0)$ & $119(13.5)$ & 0.548 \\
\hline
\end{tabular}

Data are reported as mean (SD); * between-groups statistical significance (one-factor ANOVA).

Although the knee extension variable was measured by goniometric measurement, as all the knees in the study presented a value $=0^{\circ}$, or full extension, it is neither presented nor analyzed in the present study. 


\subsection{Analysis of Outcome Measures about Disability}

Table 3 includes the initial and final scores of the variables in the study, and the differences between measurements before and after treatment.

Table 3. Baseline, post-intervention, and mean score changes of knee pain and lower extremity function.

\begin{tabular}{|c|c|c|c|c|}
\hline & Baseline & $\begin{array}{c}\text { Post- } \\
\text { Intervention }\end{array}$ & $\begin{array}{l}\text { Within-Group } \\
\text { Mean Changes }\end{array}$ & $\begin{array}{c}\text { Between-Groups } \\
\text { Mean Changes }\end{array}$ \\
\hline \multicolumn{5}{|c|}{ LEFS } \\
\hline $\begin{array}{l}\text { Control } \\
\text { TPE }\end{array}$ & $\begin{array}{c}47(8.9) \\
45(15.2)\end{array}$ & $\begin{array}{l}50(10.3) \\
60(9.0)\end{array}$ & $\begin{array}{c}3[1 / 5] \\
15[9 / 19]^{* *}\end{array}$ & $10[3 / 14]^{\dagger}$ \\
\hline \multicolumn{5}{|c|}{ KUJALA } \\
\hline $\begin{array}{l}\text { Control } \\
\text { TPE }\end{array}$ & $\begin{array}{l}50(13.7) \\
49(14.9)\end{array}$ & $\begin{array}{l}53(12.5) \\
69(13.1)\end{array}$ & $\begin{array}{c}3[1 / 5]^{*} \\
20[16 / 23]\end{array}$ & $16[8 / 22]^{++}$ \\
\hline \multicolumn{5}{|c|}{ DN4 } \\
\hline $\begin{array}{l}\text { Control } \\
\text { TPE }\end{array}$ & $\begin{array}{l}3.8(1.9) \\
3.8(1.3)\end{array}$ & $\begin{array}{c}4(1.9) \\
1.9(1.1)\end{array}$ & $\begin{array}{c}0.2[0.1 / 0.4] \\
1.9[1.3 / 2.3]^{* *}\end{array}$ & $2.1[1.1 / 2.9]^{\dagger+}$ \\
\hline \multicolumn{5}{|c|}{ VAS } \\
\hline $\begin{array}{l}\text { Control } \\
\text { TPE }\end{array}$ & $\begin{array}{l}63(17.6) \\
58(12.1)\end{array}$ & $\begin{array}{l}63(18.8) \\
48(13.1)\end{array}$ & $\begin{array}{c}0[-2 / 3] \\
10[3.7 / 15]\end{array}$ & $15[5 / 23]^{\dagger}$ \\
\hline \multicolumn{5}{|c|}{ FLEXION } \\
\hline $\begin{array}{l}\text { Control } \\
\text { TPE }\end{array}$ & $\begin{array}{l}110(16.2) \\
117(11.0)\end{array}$ & $\begin{array}{l}111(16.5) \\
126(12.3)\end{array}$ & $\begin{array}{c}1[-3 / 2] \\
9[5 / 13]^{* *}\end{array}$ & $15[4 / 24]^{\dagger}$ \\
\hline
\end{tabular}

LEFS: Low extremity functionality scale; DN4: Neuropathic pain in four questions; VAS: visual analogue scale. Data are reported as mean (SD) or (95\% confidence level); * indicates statistically significant withingroup differences $(p<0.05) ;{ }^{* *}$ indicates statistically significant within-group differences $(p<0.001) ;{ }^{\dagger}$ indicates statistically significant within-group differences $(p<0.05) ;{ }^{+\dagger}$ indicates statistically significant between-groups differences $(p<0.001)$.

Statistical significance was found in favor of the experimental group in the betweengroups comparison and in the interaction in the covariables age, height, weight and body mass index, in both the perception of pain: VAS $\mathrm{F}_{1,53}=4.77(p=0.001) \eta^{2}=0.33$ and DN4 $\mathrm{F}_{1,53}=6.99(p<0.001) \eta^{2}=0.42$; and in the knee disability index: LEFS: $\mathrm{F}_{1,53}=4.38$ $(p=0.002) \eta^{2}=0.31$ and KUJALA: $\mathrm{F}_{1,53}=10.58(p<0.001) \eta^{2}=0.52$; as well as, finally, in range of movement: Flexion: $F_{1,53}=6.35(p<0.001) \eta^{2}=0.50$. No statistically differences were found between before- and after-treatment measurements regarding the use of basic analgesic drugs. Finally, it must be considered that no side effects were observed.

\section{Discussion}

In this study, we evaluated the effectiveness of a telematic TPE program, supervised by a physiotherapist, in reducing pain and disability in patients with PFPS. In all participants, a significant improvement was observed in pain intensity, range of movement, and disability from baseline to four weeks of treatment, according to VAS, LEFS, DN4, and KUJALA indices.

According to the most recent systematic reviews on the approach to PFPS, TPE is by far the most used therapeutic alternative [24]. Both due to its effectiveness as a treatment, and due to the ease of carrying it out in the home environment-needing few resources and given the situation of confinement that our target population was subjected to-practically no other alternative was left.

In the abovementioned reviews, the primary option is pointed out as eccentric muscle work, demonstrating a more important improvement in functional balance, as well as patient satisfaction, than other alternatives [25]. This effectiveness would be related to the increase in production of collagen at the quadriceps tendon level and correct alignment of 
the new fibers synthesized, thereby improving their structure. Likewise, the formation of new vessels is produced, which would lead to an attenuation of the levels of pain perceived by the nociceptive nerve fibers present in the structure. Despite the numerous studies conducted, exercise type, frequency, and load are highly variable in the different studies included in the systematic reviews [26].

This makes it absolutely essential to carry out more comprehensive studies in the future $[6,27]$. Meanwhile, isometric exercise has also been pointed out as one of the most interesting therapeutic alternatives to tackle PFPS. It is above all due to the analgesic effect it induces nearly immediately, which lasts for $45 \mathrm{~min}$ after being carried out, practically from the first few sessions. This analgesia is related to muscular inhibition at the cortical level. This makes isometric exercise a tool of great clinical usefulness. For this reason, we guide our patients to do this before and after carrying out the therapeutic exercise program, recommending that they leave the exercises that involve concentric or eccentric work or subject the knee joint to loads to the middle of the program. Thus, we make the most of this induced analgesia by using it to our advantage to boost the therapeutic adherence of our patients $[4,27]$.

One of the limitations of our study was the relatively short-term follow-up of four weeks due to the lack of adherence to the treatment of our subjects, which in our case was limited to three subjects (who did not finish the study) per group.

Another limitation was the methods used for telecommunications, i.e., phone and email (and audiovisual resources and links to online material only if it was necessary) but not videoconference. It is obvious that by increasing the attractiveness of home-based programs, we can facilitate patient adherence to tele-rehabilitation [17].

One of the strengths of our study was the fast adaptation of the physiotherapy service to the pandemic, with low resources available, so as not to interrupt the treatment of patients. Another of the strengths is the similarity between our participants' characteristics and those of participants in other studies. This may help other researchers to achieve a common conclusion by reviewing these study results.

\section{Conclusions}

The perceived pain in patients with PFPS after the application of a TPE protocol supervised by a physiotherapist via telematic channels was reduced on average by $1 / 10$, measured using the VAS and DN4 scales.

Application of TPE supervised by a physiotherapist via telematic channels was effective and produced changes in the degree of disability of patients afflicted with PFPS measured through the LEFS with an increase of 15 points, rising from 45 to 60 .

Measurement of this disability using the KUJALA questionnaire presented a mean reduction of 20 points, going from 49 to 69 .

Finally, it was determined that range of movement was increased by an average of $9^{\circ}$.

It can be concluded, therefore, that therapeutic exercise supervised by a physiotherapist via telematic channels demonstrates greater effectiveness in pain reduction and disability in patients afflicted with PFPS than merely providing information sheets to the patient.

Author Contributions: Conceptualization, M.A.-C. and I.E.-P.; methodology, M.A.-C. and L.E.-A.; software, A.M.B.-Q.; validation, C.J.B.-Q., A.M.B.-Q. and M.d.l.A.C.-D.; formal analysis, M.A.-C.; investigation, C.J.B.-Q.; resources, C.J.B.-Q.; data curation, C.J.B.-Q., A.M.B.-Q. and M.d.I.A.C.-D.; writing — original draft preparation, I.E.-P.; writing—review and editing, I.E.-P.; visualization, L.E.-A.; supervision, I.E.-P.; project administration, M.A.-C. All authors have read and agreed to the published version of the manuscript.

Funding: This research received no external funding.

Institutional Review Board Statement: The study was conducted according to the guidelines of the Declaration of Helsinki and approved by committee CEI UNIVERSITY HOSPITAL VIRGEN MACARENA and VIRGEN DEL ROCÍO, (with ethics approval number 41255cfc9ab78019f9a8501bb35 
4b0ba4b15a804, dated 06/04/2019), and registered in the Australian New Zealand Clinical Trials Registry (registration number: ACTRN 12619001457134, dated 22/10/2019).

Informed Consent Statement: Informed consent was obtained from all subjects involved in the study.

Acknowledgments: The authors would like to thank all of the patients in the Physiotherapy Service of the San José de la Rinconada Health Center (Seville), dependent on the Andalusian Health Service, for their collaboration.

Conflicts of Interest: The authors declare no conflict of interest. The authors alone are responsible for the content and writing of the article.

\section{References}

1. Reordenación de la Actividad de Fisioterapia en Atención Primaria Para Abordar la Situación Sanitaria Provocada Por Covid-19. n.d. Available online: http:/ / www.aefi.net/Portals/1/coronavirus/Reordenacio \%CC $\% 81$ \% $\% 20$ actividad $\% 20$ UFAP $\% 20$ Abril $\%$ 202020.pdf (accessed on 25 April 2020).

2. Briani, R.V.; Ferreira, A.S.; Pazzinatto, M.F.; Pappas, E.; De Oliveira Silva, D.; Azevedo, F.M. What interventions can improve quality of life or psychosocial factors of individuals with knee osteoarthritis? A systematic review with meta-analysis of primary outcomes from randomised controlled trials. Br. J. Sports Med. 2018, 52, 1031-1038. [CrossRef]

3. Castro-Sanchez, A.M.; Matarán-Peñarrocha, G.A.; Gómez-García, S.; García-López, H.; Andronis, L.; Albornoz-Cabello, M.; Lara-Palomo, I.C. Study protocol randomised controlled trial comparison of cost-utility and cost-effectiveness of a face-to-face rehabilitation programme versus a telemedicine programme in the treatment of patients with chronic low back pain. BMJ Open 2020, 10, e040633. [CrossRef]

4. Collins, N.J.; Crossley, K.M.; Darnell, R.; Vicenzino, B. Predictors of short and long term outcome in patellofemoral pain syndrome: A prospective longitudinal study. BMC Musculoskelet. Disord. 2010, 11, 11. [CrossRef] [PubMed]

5. Satkunskiene, D.; Mickevicius, M.; Snieckus, A.; Kamandulis, S. Leg stiffness, valgus knee motion, and Q-angle are associated with hypertrophic soft patella tendon and idiopathic knee pain in adolescent basketball players. J. Sports. Med. Phys. Fit. 2017, 57, 1003-1013. [CrossRef]

6. Wood, L.; Muller, S.; Peat, G. The epidemiology of patellofemoral disorders in adulthood: A review of routine general practice morbidity recording. Prim. Health Care Res. Dev. 2011, 12, 157-164. [CrossRef]

7. Hart, H.F.; Barton, C.J.; Khan, K.M.; Riel, H.; Crossley, K.M. Is body mass index associated with patellofemoral pain and patellofemoral osteoarthritis? A systematic review and meta-regression and analysis. Br. J. Sports Med. 2017, 51, 781-790. [CrossRef]

8. Rothermich, M.A.; Glaviano, N.R.; Li, J.; Hart, J.M. Patellofemoral pain: Epidemiology, pathophysiology, and treatment options. Clin. Sports Med. 2015, 34, 313-327. [CrossRef]

9. Crossley, K.; Bennellm, K.; Green, S.; McConnell, J. A systematic review of physical interventions for patellofemoral pain syndrome. Clin. J. Sports Med. 2001, 11, 103-110. [CrossRef]

10. Insall, J. Current concepts review: Patellar pain. J. Bone Jt. Surg. Am. 1982, 64, 147-152. [CrossRef]

11. Logan, C.A.; Bhashyam, A.R.; Tisosky, A.J.; Haber, D.B.; Jorgensen, A.; Roy, A.; Provencher, M.T. Systematic Review of the Effect of Taping Techniques on Patellofemoral Pain Syndrome. Sports Health 2017, 9, 456-461. [CrossRef]

12. Salarie Sker, F.; Anbarian, M.; Yazdani, A.H.; Hesari, P.; Babaei-Ghazani, A. Patellar bracing affects sEMG activity of leg and thigh muscles during stance phase in patellofemoral pain syndrome. Gait Posture 2017, 58, 7-12. [CrossRef]

13. Espí-López, G.V.; Arnal-Gómez, A.; Balasch-Bernat, M.; Inglés, M. Effectiveness of Manual Therapy Combined With Physical Therapy in Treatment of Patellofemoral Pain Syndrome: Systematic Review. J. Chiropr. Med. 2017, 16, 139-146. [CrossRef] [PubMed]

14. McConnell, J. The management of chondromalacia patellae: A long term solution. Aust. J. Physiother. 1986, 32, 215-223. [CrossRef]

15. de Oliveira Silva, D.; Pazzinatto, M.F.; Rathleff, M.S.; Holden, S.; Bell, E.; Azevedo, F.; Barton, C. Patient education for patellofemoral pain: A systematic review. J. Orthop. Sports Phys. Ther. 2020, 50, 388-396. [CrossRef] [PubMed]

16. Mirapeix, F.M.; Montilla Herrador, J.; Meseguer Henarejos, A.B.; Escolar Reina, P.; Valera Garrido, J.F.; Jimeno Serrano, F.J. ¿Puede mejorarse la validez de los protocolos para el tratamiento fisioterapico en la cervicalgia? Fisioterapia 2007, 29, 183-189. [CrossRef]

17. Azma, K.; RezaSoltani, Z.; Rezaeimoghaddam, F.; Dadarkhah, A.; Mohsenolhosseini, S. Efficacy of tele-rehabilitation compared with office-based physical therapy in patients with knee osteoarthritis: A randomized clinical trial. J. Telemed. Telecare 2018, 24, 560-565. [CrossRef] [PubMed]

18. EPIDAT: Programa para análisis epidemiológico de datos. Versión 4.2, julio 2016. Consellería de Sanidade, Xunta de Galicia, España; Organización Panamericada de la salud (OPS-OMS); Universidad CES, Colombia. Available online: https://www.sergas. es/Saude-publica/EPIDAT-4-2 (accessed on 25 April 2020).

19. Programas de ejercicios Rodilla. n.d. Available online: http:/ / www.sermef-ejercicios.org/ (accessed on 10 September 2020). 
20. Bouhassira, D.; Attal, N.; Alchaar, H.; Boureau, F.; Brochet, B.; Bruxelle, J.; Cunin, G.; Fermanian, J.; Ginies, P.; Grun-Overdyking, A.; et al. Comparison of pain syndromes associated with nervous or somatic lesions and development of a new neuropathic pain diagnostic questionnaire (DN4). Pain 2005, 114, 29-36. [CrossRef] [PubMed]

21. Gil-Gámez, J.; Pecos-Martín, D.; Kujala, U.M.; Martínez-Merinero, P.; Montañez-Aguilera, F.J.; Romero-Franco, N.; GallegoIzquierdo, T. Validation and cultural adaptation of "Kujala Score" in Spanish. Knee Surg. Sports Traumatol. Arthrosc. 2016, 24, 2845-2853. [CrossRef]

22. Binkley, J.M.; Stratford, P.W.; Lott, S.A.; Riddle, D.L. The Lower Extremity Functional Scale (LEFS): Scale development, measurement properties, and clinical application. North American Orthopaedic Rehabilitation Research Network. Phys. Ther. 1999, 79, 371-383.

23. Dworkin, R.H.; Turk, D.C.; Wyrwich, K.W.; Beaton, D.; Cleeland, C.S.; Farrar, J.T.; Haythornthwaite, J.A.; Jensen, M.P.; Kerns, R.D.; Ader, D.A.; et al. Interpreting the clinical importance of treatment outcomes in chronic pain clinical trials: IMMPACT recommendations. J. Pain 2008, 9, 105-121. [CrossRef]

24. Holden, S.; Skovdal Rathleff, M.; Bach Jensen, M.; Barton, C.J. How can we implement exercise therapy for patellofemoral pain if we don't know what was prescribed? A systematic review. Br. J. Sports Med. 2018, 52, 385. [CrossRef] [PubMed]

25. Saltychev, M.; Dutton, R.; Laimi, K.; Beaupré, G.; Virolainen, P.; Fredericson, M. Effectiveness of conservative treatment for patellofemoral pain syndrome: A systematic review and meta-analysis. J. Rehabil. Med. 2018, 50, 393-401. [CrossRef] [PubMed]

26. van der Heijden, R.A.; Lankhorst, N.E.; van Linschoten, R.; Bierma-Zeinstra, S.M.; van Middelkoop, M. Exercise for treating patellofemoral pain syndrome. Cochrane Database Syst. Rev. 2015, 1, CD010387. [CrossRef] [PubMed]

27. de la Fuente, A.; Valero, B.; Cuadrado, N. Physiotherapeutic management of patellar tendinopathy: Sistematic review. Fisioterapia 2019, 41, 131-142. [CrossRef] 